Article

\title{
Pulse Width and Frequency Hybrid Modulated LLC Converter Adapted to Ultra Wide Voltage Range
}

\author{
Umar Khalid ${ }^{1, *}$, Muhammad Mansoor Khan ${ }^{1}$, Muhammad Zahid Khan ${ }^{1}$, \\ Muhammad Ahmad Usman Rasool ${ }^{1}$ and Jianming $\mathrm{Xu}^{2}$ \\ 1 School of Electronic, Information and Electrical Engineering (SEIEE), Shanghai Jiao Tong University, \\ Shanghai 200240, China; mansoor@sjtu.edu.cn (M.M.K.), zahid@sjtu.edu.cn (M.Z.K.); \\ iamahmedusman@sjtu.edu.cn (M.A.U.R.) \\ 2 Changzhou Power Supply Company, Changzhou 213000, China; czxjm@sohu.com \\ * Correspondence: umarkhalidd@outlook.com
}

Received: 18 September 2018; Accepted: 7 November 2018; Published: 11 November 2018

\begin{abstract}
In wide voltage range applications such as electric vehicles (EVs) onboard charging, conventional frequency modulated LLC topology has its intrinsic limitations. Its frequency span is extremely wide and the soft switching feature might get lost. To address this issue, this paper proposes a novel LLC resonant converter. The pulse width and frequency hybrid modulation are adopted to narrow down its switching frequency span. The operating principles, circuit modeling, and the design methodology are presented. A $1 \mathrm{~kW}$ rated prototype has been built to realize an efficient power flow between the $400 \mathrm{~V}$ DC bus and 200-440 V battery pack. The designed prototype validates the effectiveness of the proposed topology and modulation method. $96.8 \%$ peak efficiency is measured for the constructed experimental prototype.
\end{abstract}

Keywords: LLC; resonant converter; PWM; EV chargers

\section{Introduction}

Recently, hybrid, plug-in hybrid and electric vehicles (HEVs, PHEVs, and EVs) have gained popularity as promising automotive products due to numerous advantages, such as increased vehicle performance and fuel economy. They also help in reducing environmental pollution by controlling the emissions of greenhouse gases [1]. EVs connected to the grid may be utilized as an ancillary service provider as they can be instrumental in reactive power support and load balancing [2]. As EVs are gaining popularity, researchers are trying to address the three main issues, including cost of batteries, optimal design of chargers and improved charging infrastructure [3]. EV chargers are typically classified as off-board charges and on-board chargers with or without bidirectional capability. While designing EV on-board chargers, size and weight are major constraints [2].

DC-DC converters are an integral part of EVs onboard chargers [2]. The DC-DC stage of Plugin EVs chargers mainly consist of LLC resonant topology [4-6]. LLC resonant topology has a simple structure and reduced EMI. Moreover, switching losses can be decreased by extending the zero voltage switching (ZVS) and zero current switching (ZCS) range of MOSFETs and power diodes respectively [7-9]. Hence, LLC is regarded as the more suitable structure opted for EVs chargers [10-12]. An EV charger needs to operate at higher efficiency at the wide voltage variation range. If the LLC converter has to meet such a wide voltage range, the switching frequency $\left(f_{s}\right)$ needs to be varied and deviates from resonant frequency $\left(f_{r}\right)$ as demonstrated in Figure 1 where voltage gain requirements are met by varying the switching frequency. This variation in fs degrades the converter efficiency and thus it is desired that either the converter operates at its resonant frequency under all load 
conditions or $f_{s}$ doesn't deviate a lot from $f_{r}$. Thus, the converter operational frequency range should be minimized $[6,13,14]$.

If low voltage gain is required, the converter has to operate in region 2 as shown in Figure 1. In this region, power diodes will lose ZCS, leading to an increased switching loss. If high voltage gain is required, LLC converter has to operate at much lower frequency than resonance. This leads to the problems in designing optimal circuit magnetics such as transformer core [6].

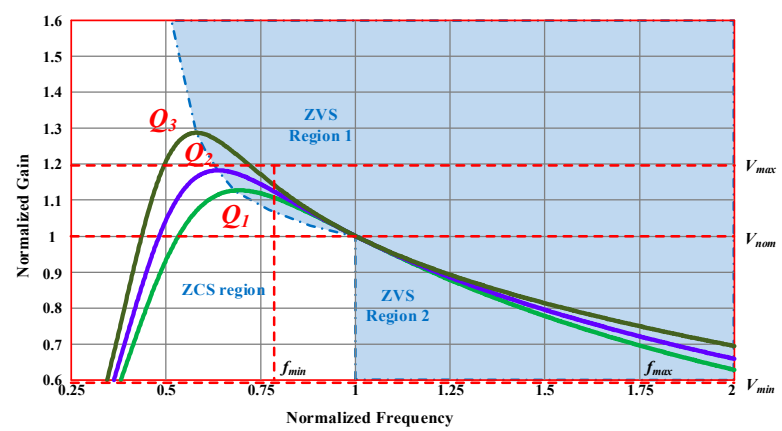

Figure 1. Gain analysis of a typical LLC resonant converter.

Numerous techniques to narrow down the LLC converter operation frequency have been proposed in the literature [8,15-18]. In [8], the designed LLC converter is incorporated with a two-phase interleaved boost circuit. However, the converter power density is severely affected by additional circuit components. In [16-18], burst mode (BM) approach is engaged under low load conditions. However, electromagnetic interference (EMI) issues have been reported due to some high frequency oscillations. In order to eliminate such EMI issues, pulse frequency modulation (PFM) and phase shift (PS) control are combined in [19]. But efficiency degrades due to high circulating currents when phase shift is utilized for a wide voltage range. In [20], asymmetric pulse width modulation (APWM) is adopted at the primary side in order to boost the conversion ratio, but voltage gain is still strongly dependent on load.

In $[17,21-24]$ various operation modes like synchronous rectification (SR), BM, PS, APWM, Pulse-width modulation (PWM) are studied for resonant converter to work with PFM control. Although proposed operational modes in the literature extend the gain requirements and narrow down the switching frequency range, they have their own limitations. BM presents a severe EMI problem, while the conversion ratio of SR, APWM and PWM are not independent of the load conditions. Promising techniques for wide voltage range DC applications have been discussed in [25], but topology structure and control is complicated.

In this paper, a LLC topology with PWM and PFM hybrid modulation have been proposed. PWM is introduced to the secondary side auxiliary switch to make the voltage regulation independent of the load. Therefore, the main LLC topology is designed to work at its resonant frequency under most of the load conditions and thus never lose ZVS under light load conditions. Furthermore, by making the auxiliary switch constantly on/off, the secondary sides switch networks can reconfigure between half and full bridges structures. This helps to further extend the voltage gain range. Last but not the least, in extreme voltage scenarios, frequency modulation can be activated to extend the voltage gain range even further. To summarize, the benefits of the proposed topology include: (1) an ultra-wide voltage gain range; (2) wide soft-switching range; and (3) load independent PWM based voltage regulation.

\section{Proposed Hybrid LLC Converter}

\subsection{Topology Description}

In this paper, a LLC topology is proposed, as shown in Figure 2. This DC-DC resonant converter topology has been derived from the full-bridge LLC topology with voltage doubler structure at the 
secondary side of the transformer. In comparison with the orthodox voltage doubler configuration, an active switch has been added controlled by PWM. The duty cycle of this additional switch determine the output voltage of the converter. Hence, under most of the load conditions, converter operates at resonant frequency. While PFM can also be used to meet the high voltage output conditions.

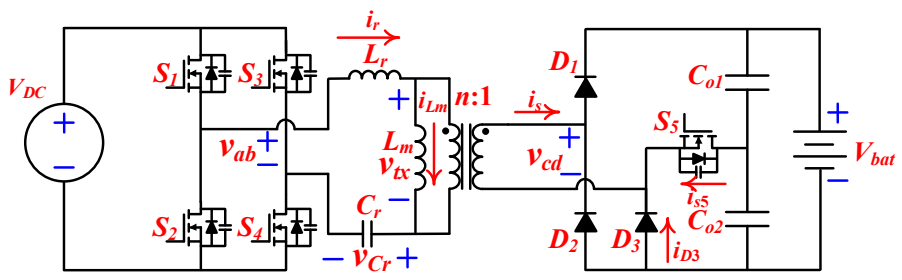

Figure 2. Proposed Pulse-width modulation (PWM)-LLC Topology with reconfigurable structure.

\subsection{Operation Principle}

The control strategies for the proposed converter are demonstrated in Table 1. In forward mode, the output voltage ranges of 200-440 has been met with a constant input voltage of $400 \mathrm{~V}$ with 2:1 transformer turns ratio (n:1).

Table 1. Forward mode Control and Configuration Characteristics.

\begin{tabular}{ccccc}
\hline $\mathbf{V}_{\mathbf{o}}$ (V) Output & Modulation Mode & $\begin{array}{c}\text { Inverter Side } \\
\text { Configuration }\end{array}$ & $\begin{array}{c}\text { Rectification Side } \\
\text { Configuration }\end{array}$ & $\begin{array}{c}\text { Operating } \\
\text { Frequency }\end{array}$ \\
\hline $200-400$ & PWM & Full Bridge & PWM Controlled $S_{5}$ & $f_{r}$ \\
$400-440$ & PFM & Full Bridge & Voltage Doubler & $<f_{r}$ \\
\hline
\end{tabular}

Detailed operational stages in PWM shown in Figure 3 have been briefly discussed here and the corresponding equivalent circuits are shown in Figure 4 . The switching frequency of $\mathrm{S}_{5}$ is also equal to $f_{r}$. On the secondary side, a minor phase shift $\left(t_{\text {delay }}\right)$ is introduced between the switching on of $S_{5}$ and $t_{\text {dead }}$. This makes sure that the body diode of $S_{5}$ conducts earlier in case of forward mode than the turn-on of the $S_{5}$. Generally, the duty cycle of $V_{\text {gs5 }}$ (D) should be controlled within the range of $(0.5,1)$.

Considering Figure 3 for PWM mode, Stage I starts at $t_{0}$ when $S_{1,4}$ are turned-off. Stage I is within the $t_{\text {dead }}$ of $S_{1-4}$. The voltage $v_{a b}$ decreases from $V_{D C} \cdot i_{r}$ charges the output capacitors $\left(C_{o s}\right)$ of $S_{2,3}$ and discharges $C_{o s}$ of $S_{1,4}$. Since $C_{o s}$ is comparatively smaller, $i_{r}$ can be realized as constant, and $V_{a b}$ decrease linearly.

$$
\begin{gathered}
v_{a b}(t)=V_{D C}-\frac{\left(t-t_{0}\right) i_{r}\left(t_{0}\right)}{C_{o s s}} \\
v_{t x}(t)=\left[v_{a b}(t)-V_{C r}\left(t_{0}\right)\right] \frac{L_{m}}{L_{m}+L_{r}}
\end{gathered}
$$

Stage II is further divided into two stages. In the first step of stage II, $V_{a b}$ and $V_{t x}$ continue to decrease. When $D_{2}$ conducts, its forward voltage drop is about zero. According to KVL, the negative $V_{t x}$ now enables body diode $D_{2}$ to be forward biased; and thus the output capacitor of $S_{5}\left(C_{s 5}\right)$ is discharged. At the second step, $S_{2,3}$ are turned $\mathrm{ON}$ and the body diode $D_{5}$ of $S_{5}$ starts conducting. In this stage, $S_{2,3}$ are turned ON with ZVS.

Stage III: $\left[t_{2}, t_{3}\right)$. At $t_{2}, S_{5}$ is turned on. At $t_{2}, S_{5}$ is turned on. It is obvious that the conduction of $S_{5}$ body diode in the former stage forms the ZVS state for the switching-on of $S_{5}$. While, at the secondary side of the converters' transformer, $D_{2}$ and $S_{5}$ both conduct. $C_{r}$ and $L_{r}$ resonate at the resonant frequency and this resonance frequency is equivalent to $f_{r}$.

Stage IV $\left[t_{3}, t_{4}\right) . i_{s}$ stays zero after $t_{3}$. Thus, the transformer secondary side is open-circuited. $L_{m}$ joins the resonance with $L_{r}$ and $C_{r}$. $i_{r}$ equals to $i_{L m}$ and varies sinusoidal. Stage $\mathrm{V}\left[t_{4}, t_{5}\right)$. is within the deadband of $S_{1-4}$ and thus, the circuit operation in this stage is similar to that in stage I. 


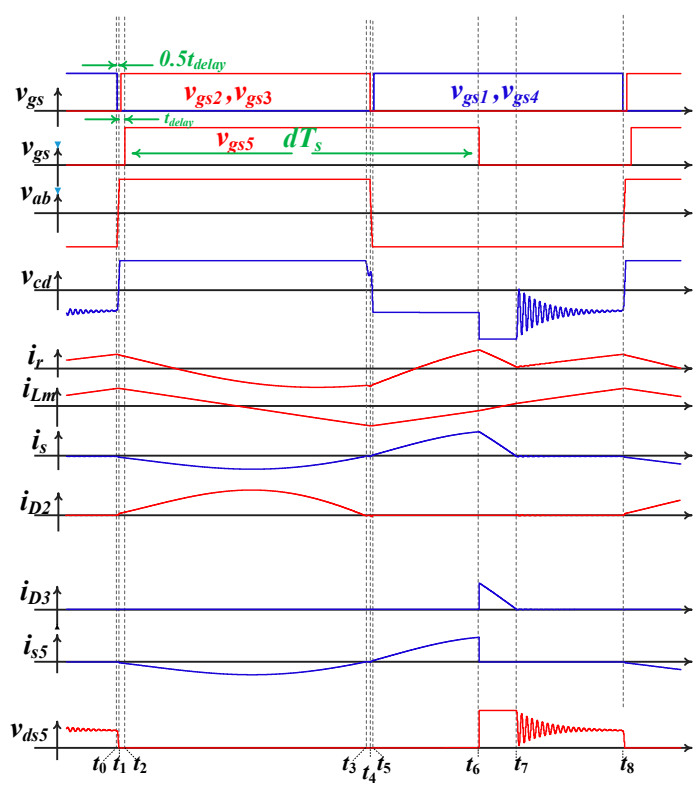

Figure 3. Operational Principle in PWM mode.

At $t_{5}$, the deadband is over and $v_{a b}$ increases to $V_{D C}$. Before the channels are turned ON, the drain to source voltages of switches $S_{1,4}$ are discharged to zero. Thus, the turning on of $S_{1,4}$ is ZVS. At $t_{5}$, $S_{1,4}$ are turned ON and stage VI starts. In this stage, $V_{a b}$ is equivalent to $V_{D C}$. $i_{s}$ is positive and body diode $D_{5}$ of $S_{5}$ conducts as shown in Figure $4 \mathrm{f}$. $S_{5}$ is turned off at $t_{6}$ and Stage VII begins. As the primary side inductor current is continuous, the current path is moved from $S_{5}$ to $D_{3}$. At $t_{7}$, $i_{s}$ becomes zero and the circuit enters into stage VIII. Since $S_{1,4}$ are still $\mathrm{ON}, i_{S}$ remains zero. Therefore, the power devices on the secondary side are not ON. Stage VIII ends when $S_{1,4}$ are turned off.

During PFM mode in forward mode, the converter operates at a frequency lower than its designed resonant frequency $\left(f_{r}\right)$ such that it operates in region 1 of PFM gain curve discussed below. In this way, converter MOSFETs will always operate in ZVS condition while power diodes will operate under ZCS condition. The secondary side will act as the voltage doubler as the D of $S_{5}$ will have a value 1 .
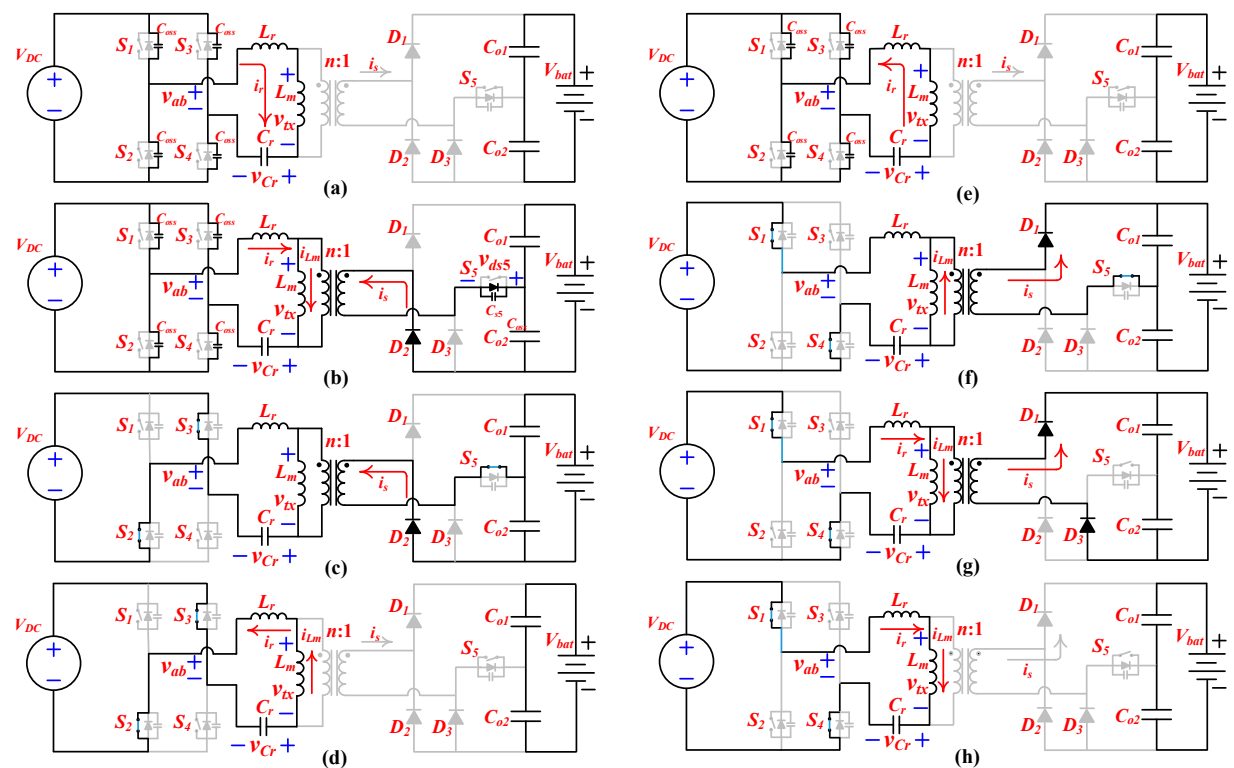

Figure 4. Converter equivalent circuits in PWM Mode: (a) Stage I, $t_{0} \leq t<t_{1}$; (b) Stage II, $t_{1} \leq t<t_{2}$; (c) Stage III, $t_{2} \leq t<t_{3}$; (d) Stage IV, $t_{3} \leq t<t_{4}$; (e) Stage V, $t_{4} \leq t<t_{5}$; (f) Stage VI, $t_{5} \leq t<t_{6}$; (g) Stage VII, $t_{6} \leq t<t_{7} ;$ (h) Stage VIII, $t_{7} \leq t<t_{8}$. 


\subsection{Gain Analysis}

In PWM mode, the voltage at the output of the rectifying stage is the loose function of the load. Only stages III, VI, VII are used to deliver the power. Figure 5 shows the curves of the normalized voltage gain $G_{n o r m}=n V_{o} / V_{D C}$ versus the duty cycle under diverse operative load resistances $\left(R_{L}\right)$ for PWM mode. It is worth mentioning that capacitor voltage $\left(V_{\mathrm{C} 2}\right)$ is not strongly dependent on the effective load resistance of the rectifier. Also, the duty cycle of the auxiliary switch at the secondary side has no effect on $\mathrm{V}_{\mathrm{C} 4}$.

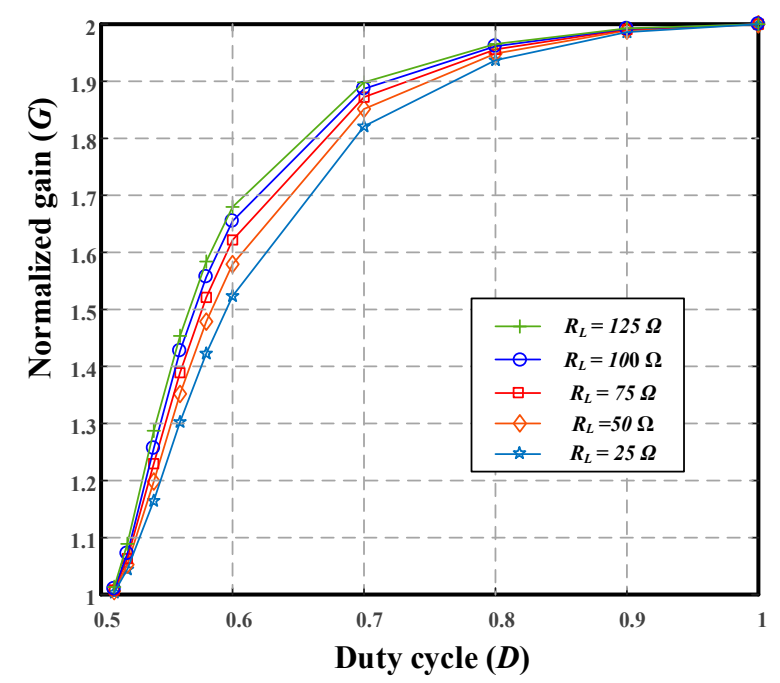

Figure 5. Voltage gain in PWM mode versus equivalent $R_{L}$ and $D$.

Gain curves in PFM mode for the proposed LLC resonant converter have been shown in Figure 6. These gain curves are based on the PFM_LLC gain expression for the voltage doubler configuration derived below using first harmonic analysis [26,27]:

$$
\begin{gathered}
G_{P F M_{-} L L C}=\frac{V_{0}}{V_{D C}}=\frac{2}{n \sqrt{Q\left(1+a+a b^{2}\right)^{2}+a^{2} / b^{2}\left(1-b^{2}\right)^{2}}} \\
a=\frac{1}{k_{L}}, b=\frac{1}{f_{n}} \\
k_{L}=\frac{L_{m}}{L_{r}}, f_{n}=\frac{f_{s}}{f_{r}}, f_{r}=\frac{1}{2 \pi \sqrt{L_{r} C_{r}}}, Q=\frac{\sqrt{\frac{L_{r}}{C_{r}}}}{R_{e q}} \\
R_{e q}=\frac{4 n^{2}}{\pi^{2}} R_{L}
\end{gathered}
$$

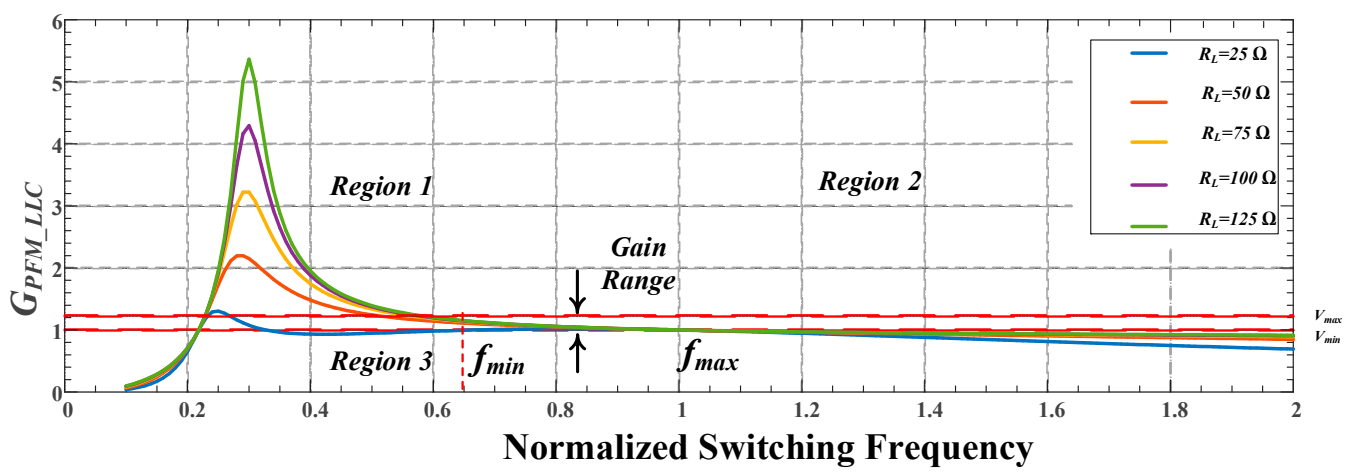

Figure 6. Gain curves of the proposed converter under pulse frequency modulation (PFM) in FM. 


\subsection{MOSFETS ZVS}

ZVS is ensured in the MOSFETs if the current flowing through these switches is negative at the instant they are turned ON. During the dead-time, the current flowing through the primary side should be able to charge and discharge the output capacitance of the primary side MOSFETs. The value of this current is dependent on Lm and the $t_{\text {dead }}$. Thus, ZVS depends on $f_{s}, t_{\text {dead }}, L_{m}$ and $C_{\text {oss }}$. So, the magnetizing inductance can be designed using the same expression as the full-bridge LLC resonant converter [19] to ensure ZVS condition. This relationship is:

$$
L_{m}=\frac{T\left(t_{\text {dead }}\right)}{16\left(C_{\text {oss }}\right)}
$$

Therefore, $t_{\text {delay }}$ and $t_{\text {dead }}$ can be well designed to ensure the ZVS of $S_{1-5}$ over the full load range.

\section{Design Example}

Consider a design example of $1 \mathrm{~kW}$ prototype with a constant DC input of $400 \mathrm{~V}$ to meet the output voltage requirement of $200-440 \mathrm{Vdc}$. The resonant frequency is chosen to be $100 \mathrm{kHz}$ for the proposed design. The transformer turns ratio is 2:1 provided that nominal battery voltage is $400 \mathrm{Vdc}$, and the converter can operate in voltage doubler configuration. Thus, to meet the voltage output of $200-400$ Vdc, PWM mode is used as shown in Figure 5. While PFM is used to meet the output voltage requirement of $400-440 \mathrm{~V}$ provided that rectifier is in voltage doubler mode. For a resonant frequency of $100 \mathrm{kHz}$, the $\mathrm{C}_{\mathrm{oss}}$ of the MOSFET is $250 \mathrm{pF}$, and the dead-time is $200 \mathrm{~ns}$, the converters' magnetizing inductance is calculated as $L_{m} \leq=500 \mu \mathrm{H}$. This indicates that the magnetizing inductance of $500 \mu \mathrm{H}$ or less ensures ZVS turning-on of the primary-side MOSFETs. $L_{m}$ can't be too large and can't be too small. An optimal value of magnetizing inductance has to be designed such that required gain can be achieved while limiting circulating currents. Careful simulations and repeated experiments are done to calculate the magnetic components parameters and resonance capacitance value.

The input voltage is $400 \mathrm{~V}$ while PFM is utilized for the output voltage of 400-440 V. The required gain is 1-1.10 in the forward PFM mode as shown in Figure 6. In order to make the gain curve monotonically decrease and also to encounter with the voltage gain requirements $L_{m}, L_{r}, C_{r}$ are calculated as following:

$$
L_{m}=200 \mu \mathrm{H}, k_{L}=10, L_{r}=20 \mu \mathrm{H}, C_{r}=125 \mathrm{nC}
$$

\section{Experimental Results}

A 1-kW prototype of PWM-LLC DC-DC converter is constructed with $400 \mathrm{~V}$ input voltage and 200-440 V output voltage. The experimental prototype has been shown in Figure 7 . This power level is selected mainly to verify the proof of concept. Resistive load (RL) is used to as the output load in this experiment. The circuit parameters are shown in Table 2. Figure 8 shows the waveform for the converter at $\mathrm{D}=1$ whereas rectification stage acts as the voltage doubler. Figure 9 shows the ZVS condition of auxillary secondary side switch while Figure 10 describes the waveform for duty cycle less than 1. Figure 11 shows the converter operating at PFM mode where $D=1$, but operating frequency is less than the designed resonant frequency. The calculated efficiency has been shown in Figure 12 for various output voltages calculated by open loop experiments. 
Table 2. Design Parameters of the Prototypes.

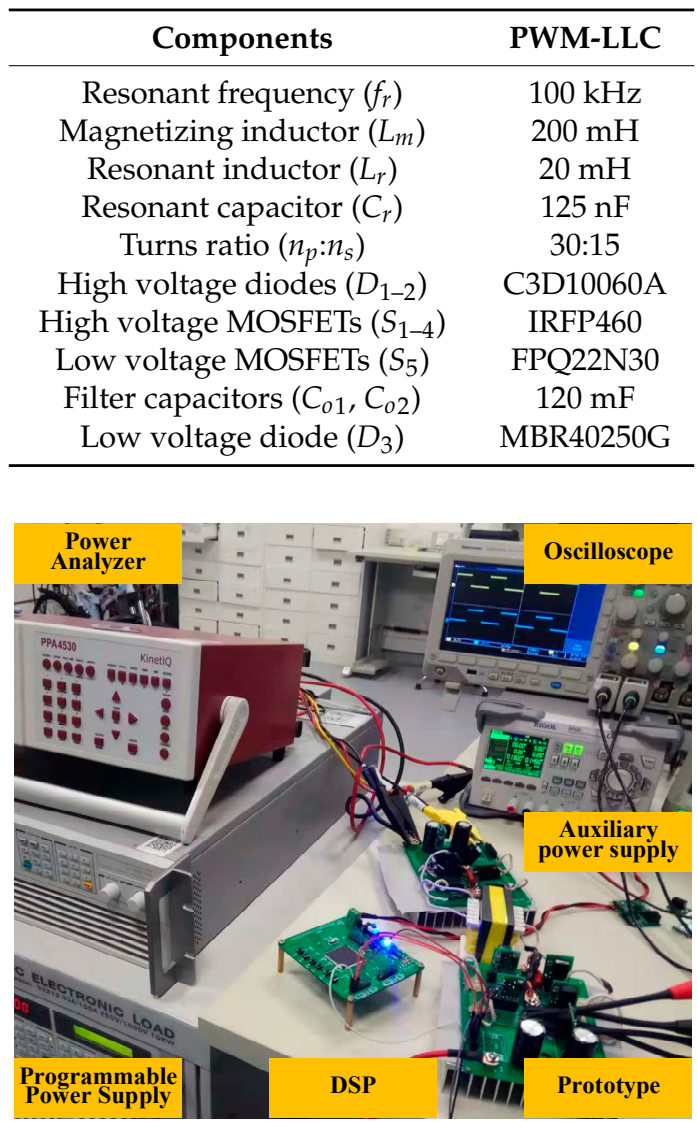

Figure 7. Experimental Prototype.

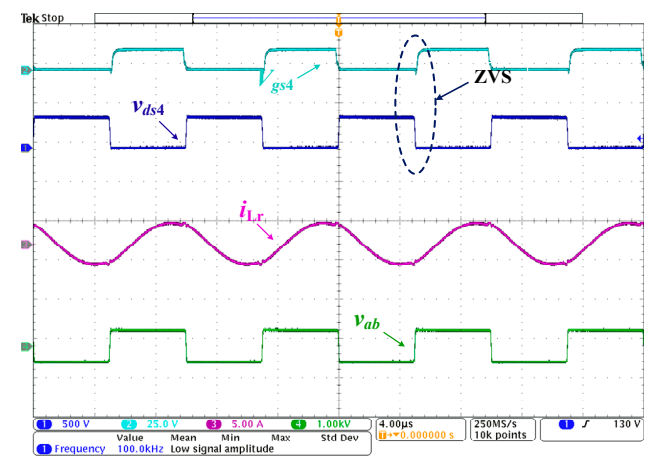

Figure 8. $\mathrm{D}_{\mathrm{Vgs} 5}=1, R_{L}=50 \mathrm{ohm}, \mathrm{Vo}=400 \mathrm{~V}, f_{s}=100 \mathrm{kHz}$.

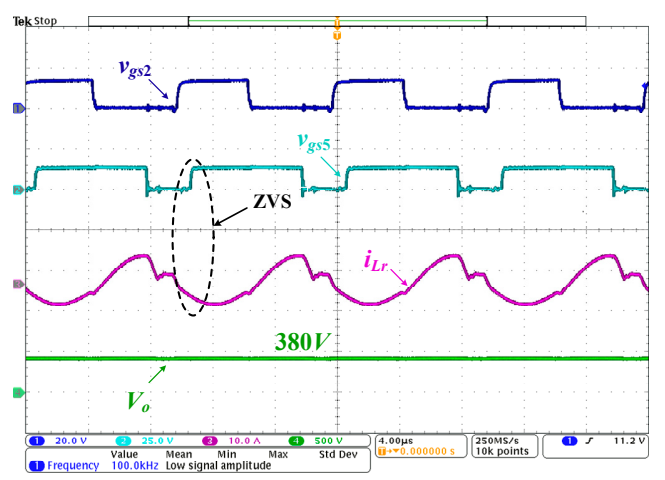

Figure 9. $\mathrm{D}_{\mathrm{Vgs} 5}=0.85, R_{L}=50 \mathrm{ohm}, \mathrm{Vo}=380 \mathrm{~V}, f_{\mathrm{s}}=100 \mathrm{kHz}$. 


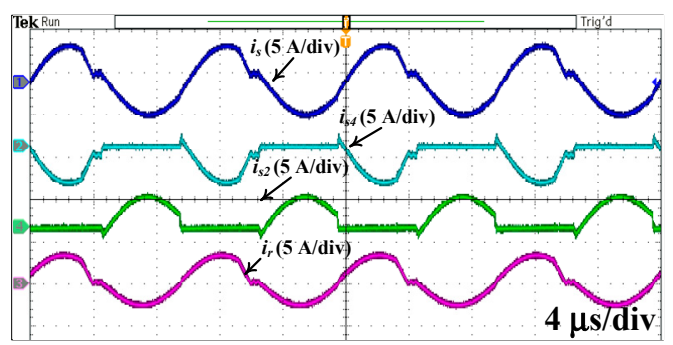

Figure 10. $\mathrm{D}_{\mathrm{Vgs} 5}=0.9, R_{\mathrm{L}}=100 \mathrm{ohm}, \mathrm{Vo}=390 \mathrm{~V}, f_{s}=100 \mathrm{kHz}$.

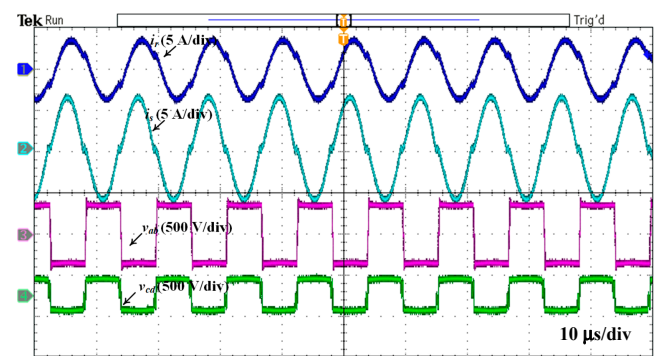

Figure 11. $\mathrm{D}_{\mathrm{Vgs} 5}=1, R_{L}=100 \mathrm{ohm}, \mathrm{Vo}=440 \mathrm{~V}, f_{\mathrm{s}}=85 \mathrm{kHz}$

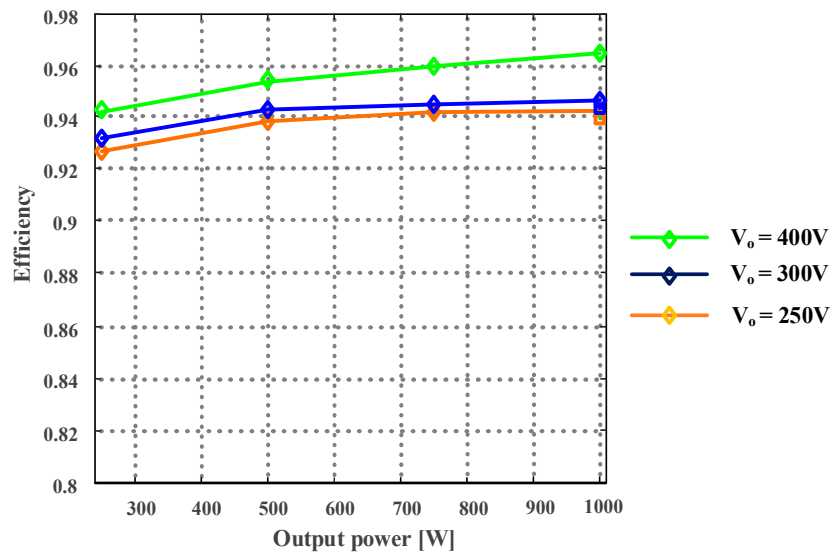

Figure 12. Experimental Efficiency.

\section{Conclusions}

In the proposed work, a novel idea to regulate output voltage has been introduced by utilizing an additional auxiliary switch at the secondary side and controlling its PWM. The proposed resonant LLC converter maximizes the converter efficiency by ensuring the ZVS and ZCS condition of MOSFETs and power diodes. A $1 \mathrm{~kW}$ prototype has been constructed to verify the concept that matches the power ratings of a typical Level $1 \mathrm{EV}$ charger. The measured peak efficiency of the constructed prototype is $96.8 \%$ for the output voltage of $400 \mathrm{~V}$ at $100 \mathrm{kHz}$. The experimental results verify the load independent voltage regulation of the proposed topology. The proposed work doesn't explain the control of the prototype as per the charging profile of EV batteries, as the application of the proposed LLC converter is not limited to EV charging requirements, but also feasible for any application that require wide voltage range. In future work, the detailed operation and control of the proposed topology according to the charging profile of the EV battery will be discussed and analyzed.

Author Contributions: Conceptualization, U.K.; Methodology, M.A.U.R.; Resources, M.Z.K.; Supervision, M.M.K.; Validation, J.X.

Funding: This research received no external funding.

Conflicts of Interest: The authors declare no conflict of interest. 


\section{References}

1. Al-Alawi, B.M.; Bradley, T.H. Review of hybrid, plug-in hybrid, and electric vehicle market modeling Studies. Renew. Sustain. Energy Rev. 2013, 21, 190-203. [CrossRef]

2. Yilmaz, M.; Krein, P.T. Review of battery charger topologies, charging power levels, and infrastructure for plug-in electric and hybrid vehicles. IEEE Trans. Power Electron. 2013, 28, 2151-2169. [CrossRef]

3. Rubino, L.; Capasso, C.; Veneri, O. Review on plug-in electric vehicle charging architectures integrated with distributed energy sources for sustainable mobility. Appl. Energy 2017, 207, 438-464. [CrossRef]

4. Fang, X.; Hu, H.; Shen, Z.J.; Batarseh, I. Operation mode analysis and peak gain approximation of the LLC resonant converter. IEEE Trans. Power Electron. 2012, 27, 1985-1995. [CrossRef]

5. Khaligh, A.; Dusmez, S. Comprehensive Topological Analysis of Conductive and Inductive Charging Solutions for Plug-In Electric Vehicles. IEEE Trans. Veh. Technol. 2012, 61, 3475-3489. [CrossRef]

6. Wang, H.; Li, Z. A PWM LLC type resonant converter adapted to wide output range in PEV charging applications. IEEE Trans. Power Electron. 2018, 33, 3791-3801. [CrossRef]

7. Wu, H.; Zhan, X.; Xing, Y. Interleaved LLC Resonant Converter with Hybrid Rectifier and Variable-Frequency Plus Phase-Shift Control for Wide Output Voltage Range Applications. IEEE Trans. Power Electron. 2017, 32, 4246-4257. [CrossRef]

8. Sun, X.; Shen, Y.; Zhu, Y.; Guo, X. Interleaved Boost-Integrated LLC Resonant Converter with Fixed-Frequency PWM Control for Renewable Energy Generation Applications. IEEE Trans. Power Electron. 2015, 30, 4312-4326. [CrossRef]

9. Li, W.; Luo, Q.; Mei, Y.; Zong, S.; He, X.; Xia, C. Flying-Capacitor Based Hybrid LLC Converters with Input Voltage Auto-Balance Ability for High Voltage Applications. IEEE Trans. Power Electron. 2016, 31, 1908-1920. [CrossRef]

10. Gautam, D.S.; Musavi, F.; Edington, M.; Eberle, W.; Dunford, W.G. An automotive onboard 3.3-kW battery charger for PHEV application. IEEE Trans. Veh. Technol. 2012, 61, 3466-3474. [CrossRef]

11. Deng, J.; Li, S.; Hu, S.; Mi, C.C.; Ma, R. Design Methodology of LLC Resonant Converters for Electric Vehicle Battery Chargers. IEEE Trans. Veh. Technol. 2014, 63, 1581-1592. [CrossRef]

12. Wang, H.; Dusmez, S.; Khaligh, A. Maximum Efficiency Point Tracking Technique for LLC-Based PEV Chargers Through Variable DC Link Control. IEEE Trans. Ind. Electron. 2014, 61, 6041-6049. [CrossRef]

13. Lu, B.; Liu, W.; Liang, Y.; Lee, F.C.; van Wyk, J.D. Optimal Design Methodology for LLC Resonant Converter. In Proceedings of the IEEE Applied Power Electronics Conference and Exposition, Dallas, TX, USA, 19-23 March 2006.

14. He, P.; Khaligh, A. Comprehensive Analyses and Comparison of $1 \mathrm{~kW}$ Isolated DC-DC Converters for Bidirectional EV Charging Systems. IEEE Trans. Transp. Electrif. 2017, 3, 147-156. [CrossRef]

15. Kim, J.-W.; Moon, G.-W. A New LLC series resonant converter with a narrow switching frequency variation and reduced conduction losses. IEEE Trans. Power Electron. 2014, 29, 4278-4287. [CrossRef]

16. Feng, W.; Lee, F.C.; Mattavelli, P. Optimal Trajectory Control of Burst Mode for LLC Resonant Converter. IEEE Trans. Power Electron. 2013, 28, 457-466. [CrossRef]

17. Zhao, B.; Song, Q.; Liu, W.; Sun, Y. Overview of dual-active-bridge isolated bidirectional DC-DC converter for high-frequency-link power-conversion system. IEEE Trans. Power Electron. 2014, 29, 4091-4106. [CrossRef]

18. Musavi, F.; Craciun, M.; Gautam, D.S.; Eberle, W. Control strategies for wide output voltage range LLC resonant DC-DC converters in battery chargers. IEEE Trans. Veh. Technol. 2014, 63, 1117-1125. [CrossRef]

19. Shafiei, N.; Ordonez, M.; Craciun, M.; Botting, C.; Edington, M. Burst Mode Elimination in High Power LLC Resonant Battery Charger for Electric Vehicles. IEEE Trans. Power Electron. 2016, 31, 1173-1188. [CrossRef]

20. Kim, B.; Park, K.; Moon, G. Asymmetric PWM Control Scheme during Hold-Up Time for Resonant Converter. IEEE Trans. Ind. Electron. 2012, 59, 2992-2997. [CrossRef]

21. Lee, W.J.; Kim, C.E.; Moon, G.W.; Han, S.K. A new phase-shifted full-bridge converter with voltage-doublertype rectifier for high-efficiency PDP sustaining power module. IEEE Trans. Ind. Electron. 2008, 55, 2450-2458.

22. Kim, M.Y.; Kim, B.C.; Park, K.B.; Moon, G.W. LLC series resonant converter with auxiliary hold-up time compensation circuit. In Proceedings of the 8th International Conference on Power Electronics-ECCE Asia, Jeju, Korea, 30 May-3 June 2011; pp. 628-633.

23. Ajmal, F.; Pan, H.; He, C.; Chen, G.; Chen, H. Pulse-width modulation control strategy for high efficiency LLC resonant converter with light load applications. IET Power Electron. 2014, 7, 2887-2894. 
24. Park, H.P.; Jung, J.H. PWM and PFM Hybrid Control Method for LLC Resonant Converters in High Switching Frequency Operation. IEEE Trans. Ind. Electron. 2017, 64, 253-263. [CrossRef]

25. Hu, Y.; Wu, J.; Cao, W.; Xiao, W.; Li, P.; Finney, S.J.; Li, Y. Ultrahigh Step-up DC-DC Converter for Distributed Generation by Three Degrees of Freedom (3DoF) Approach. IEEE Trans. Power Electron. 2016, 31, 4930-4941.

26. Beiranvand, R.; Rashidian, B.; Zolghadri, M.R.; Alavi, S.M.H. A design procedure for optimizing the LLC resonant converter as a wide output range voltage source. IEEE Trans. Power Electron. 2012, 27, 3749-3763. [CrossRef]

27. Abdel-rahman, S. Resonant LLC Converter: Operation and Design; Infineon Technologies North America: Durham, NC, USA, 2012; pp. 1-19.

C 2018 by the authors. Licensee MDPI, Basel, Switzerland. This article is an open access article distributed under the terms and conditions of the Creative Commons Attribution (CC BY) license (http://creativecommons.org/licenses/by/4.0/). 